\title{
Unstoppable Baby Crying: Is it Only Gas Pain or not?
}

\author{
D Abdussamed Vural \\ Department of Emergency Medicine, Giresun University, Giresun, Turkey
}

\section{ABSTRACT}

Hair-thread tourniquet syndrome (HTTS) is a rare but well-documented clinical condition results in significant injury as hair or thread wraps around a digit, causes tissue swelling, pain, or possible tissue ischemia. If untreated, HTTS may result in serious events, such as amputation of the organ. In this case report, we aimed to raise awareness that the hair-thread tourniquet syndrome is a clinical situation that can be easily misinterpreted as gas colic especially by family physicians, pediatricians and emergency physicians to whom families first applied.

Keywords: Child health, colic, hair, Psychomotor Agitation, tourniquets

\section{INTRODUCTION}

The hair-thread tourniquet syndrome (HTTS) is a clinical condition that occurs as a result of the circulation disturbance of the appendages, such as hands, toes, clitoris, penis, or ears caused by hair strands or yarn and especially seen in infants. ${ }^{[1-3]}$ This clinical situation, which entered the literature very early, is rare. ${ }^{[4]}$ The uneasiness situation and unstoppable baby crying are evaluated as simple gas pain at the beginning, and this can easily be overlooked with unnecessary treatments and cannot be recognized earlier.

Please cite this article as: Vural A. Unstoppable Baby Crying: Is it Only Gas Pain or not? Anatol J Family Med 2019;2(3):132-133.

Address for correspondence: Dr. Abdussamed Vural. Department of Emergency Medicine, Giresun University, Giresun, Turkey

Phone: +90 5064811070

E-mail:

abdussamedvural@gmail.com

Received Date: 11.12 .2018

Accepted Date: 28.01.2019

Published online: 14.11.2019

OCopyright 2019 by Anatolian Journal of Family Medicine -

Available online at www.anatoljfm.org

OPEN ACCESS

In this case report, we aimed to draw attention that the HTTS is a clinical situation that may be easily misinterpreted as gas colic especially by family physicians, pediatricians and emergency physicians to whom families first applied for.

\section{CASE REPORT}

A 10-month-old male baby was brought up by his relatives with serious anxiety and unstoppable crying. Complaints continued for three days and especially on the last day, the crying and restlessness of the patient increased. No significant indication was found in the physical examination of the patient who applied to the children's clinic and symptomatic treatment was started by saying that it might be gas colic, but the complaints of the patient were not reduced. Thus, the patient applied to our emergency department. Physical examination of the patient revealed hyperemia and marked edema at the middle phalanx level of the fifth finger of the right foot and purulent drainage in the surrounding tissues was detected (Fig. 1 $a, b)$. When the patient's fingers were examined carefully, a hair-thread was seen that formed a tourniquet effect. The hair was carefully removed with the help of the scalpel (Fig. 2). The patient was prescribed with a prophylactic antibiotic and was referred to the orthopedic clinic for neurovascular follow-up. Neurovascular observations were performed for two days by the orthopedist. There was no neurovascular complication in the patient. The patient was discharged with recommendations. 

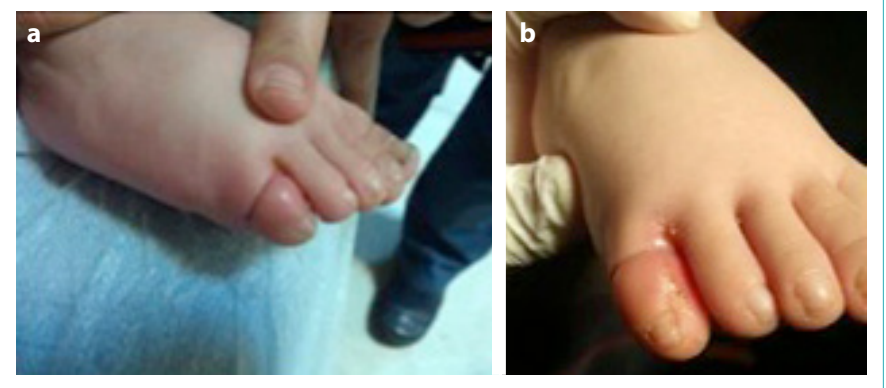

Figure $1(\mathbf{a}, \mathbf{b})$. Strangulation of the fifth finger: hyperemia and marked edema at the middle phalanx level of the fifth finger of the right foot and purulent drainage in the surrounding tissue.

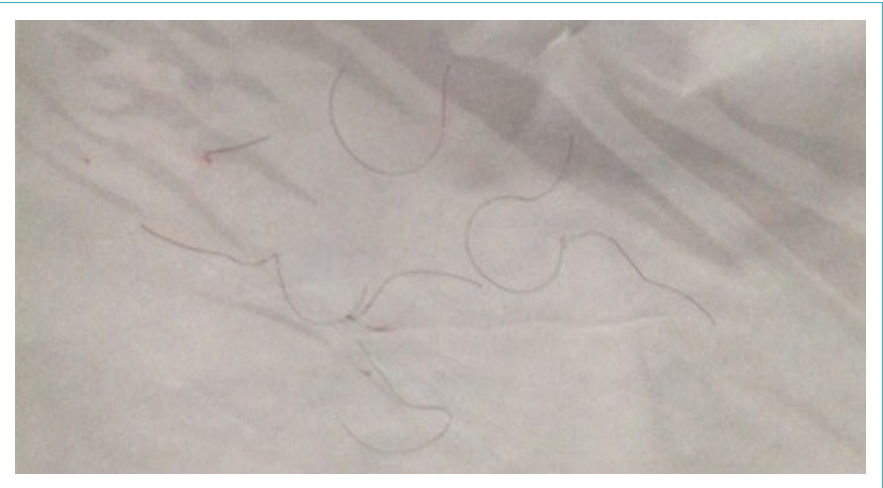

Figure 2. Hair particles removed from the tissue.

\section{DISCUSSION}

HTTS is an uncommon but well-documented clinical phenomenon results in significant injury as hair or thread wraps around a digit, causes tissue swelling, pain, or possible tissue ischemia. ${ }^{[5]}$ Approximately 100 cases of HTTS were previously described, and most occurred in the fingers $(24 \%-47 \%)$, toes $(25 \%-43 \%)$ or penises $(44 \%) .{ }^{[4,6]}$ The incidence of the phenomenon is not known, ${ }^{[5]}$ the mean age of affected children is around five months, and fingers are more frequently affected in younger children (up to 1.5 years). ${ }^{[6,7]}$ Although it is frequently seen in infants, it may be found in younger children, adolescents and adults. ${ }^{[2,8,9]}$

Differential diagnoses include infection, trauma, insect bite, and allergic or irritant dermatitis. ${ }^{[6]}$ Srinivasaiah et al. ${ }^{[8]}$ reported that the etiology was attributed to various causes, such as socio-cultural practices, non-accidental injuries, maternal telogen effluvium, Munchausen's syndrome, learning disabilities and rarely psychiatric disorders.

The diagnosis of HTTS is easily reached when the clinical picture is well known. However, it is very important not to miss HTTS because long-term HTTS may result in necrosis. ${ }^{[7]}$ The treatment of HTTS is the removal of the strangulating hair or thread. In the treatment, early diagnosis is important because treatment may be difficult if extensive local swelling has already occurred. Also, a surgical incision is often required..$^{[7]}$

\section{CONCLUSION}

Early diagnosis and treatment of HTTS are very important to prevent the occurrence of unwanted events, such as amputation of the organ. The physical examination by removal of the baby's entire clothes will allow the early detection of foreign bodies that cannot be noticed by the eye.

\section{Disclosures}

Informed consent: Written informed consent was obtained from the patient for the publication of the case report and the accompanying images.

Conflict of Interest: No conflicts of interest to be declared.

Peer-review: Externally peer-reviewed.

\section{REFERENCES}

1. Mackey S, Hettiaratchy S, Dickinson J. Hair-tourniquet syndrome--multiple toes and bilaterality. Eur J Emerg Med 2005;12(4):191-2. [CrossRef]

2. Alverson B. A genital hair tourniquet in a 9-year-old girl. Pediatr Emerg Care 2007;23(3):169-70. [CrossRef]

3. Dunphy L, Verma Y, Morhij R, Lamyman M. Hair thread tourniquet syndrome in a male infant: a rare surgical emergency. BMJ Case Reports 2017;2017. pii: bcr-2017-221002. [CrossRef]

4. Barton DJ, Sloan GM, Nichter LS, Reinisch JF. Hair-thread tourniquet syndrome. Pediatrics 1988;82(6):925-8.

5. Booth J, Morse T. Hair toe tourniquets: a review of two case studies. Emerg Nurse 2018;26(2):31-3. [CrossRef]

6. Sivathasan N, Vijayarajan L. Hair-thread tourniquet syndrome: a case report and literature review. Case Rep Med 2012;2012:171368. [CrossRef]

7. Kuiper JW, de Korte N. Hair thread tourniquet syndrome in a toe of an 18 mo old girl. World J Clin Cases 2015;3(4):368-70.

8. Srinivasaiah N, Yalamuri R, Vetrivel S, Irwin L. Limb tourniquet syndrome - a cautionary tale. Injury Extra 2008;39(4);140-2.

9. Miller RR, Baker WE, Brandeis GH. Hair-thread tourniquet syndrome in a cognitively impaired nursing home resident. Adv Skin Wound Care 2004;17(7):351-2. [CrossRef] 